\title{
IMPORTAÇÃO PARALELA E O “CASO DIESEL": UMA CARONA PERIGOSA PARA A CONCORRÊNCIA DESLEAL
}

\author{
Juliana Oliveira Domingues* \\ Aluisio de Freitas Miele**
}

\section{RESUMO}

O objetivo deste estudo é refletir sobre a importação paralela no contexto de globalização comercial à luz da jurisprudência. Para tanto, parte-se da análise de caso recente e se faz uma interpretação sistemática. Desta forma, propomos que o tema deve ser analisado diante da realidade da indústria e da necessidade de se assegurar os estímulos adequados à pesquisa e ao desenvolvimento.

Palavras-chave: Importação Paralela; Concorrência desleal; Lei de Propriedade Industrial; Jurisprudência; Pesquisa e Desenvolvimento.

\section{PARALLEL IMPORT AND THE "DIESEL CASE": A DANGEROUS RIDE FOR UNFAIR COMPETITION}

\begin{abstract}
This study has the objective to reflect on parallel import in the context of commercial globalization in the light of the case law. For this purpose, we start from the analysis of a recent case within a systematic interpretation. In this way, we propose that the topic should be analyzed based on the reality of the industry and the need to ensure appropriate incentives for research and development.
\end{abstract}

Keywords: Parallel Import; Unfair competition; Industrial Property Law; Jurisprudence; Research and Development.

\footnotetext{
* Professora Doutora de Direito Econômico do Departamento de Direito Público da Universidade de São Paulo (FDRP/USP). Advogada e Consultora. E-mail: julianadomingues@usp.br.

** Mestrando em Direito Econômico e Antitruste na Universidade de São Paulo (FDRP/USP). Graduado em Direito pela Universidade Estadual Paulista Júlio de Mesquita Filho (UNESP). Advogado. E-mail: aluisiomiele@usp.br.
} 


\section{INTRODUÇÃO}

O presente estudo foi realizado tendo por provocação a situação que se encontra a proteção jurídica das importações paralelas no Brasil.

Nesse contexto, vale destacar que o tema não é recente do ponto de vista da análise jurídica. Entretanto, apesar da Lei de Propriedade Industrial (LPI) ter trazido alguma margem de segurança no final da década de 90, ainda hoje os tribunais nacionais não possuem uma compreensão uníssona sobre este tema, o que tem resultado em decisões que caminham de maneira opostas.

Considerando que o tema tem ganhado maior importância, devido à diversificação dos canais de comércio, a intenção do presente estudo não é explorar todos os aspectos decorrentes das importações paralelas, mas adentrar nas decisões recentes do STJ e, mais especificamente, em um caso que envolve uma das indústrias mais importantes da atualidade: a indústria da moda.

Desta forma, neste estudo faremos uma breve introdução sobre o que é a importação paralela, considerando os problemas jurídicos identificados à luz da LPI e da defesa da concorrência. Os elementos trazidos nos primeiros capítulos ajudarão a compreender melhor os aspectos da decisão do Superior Tribunal de Justiça no caso "Diesel” (STJ, REsp n. ${ }^{\circ}$ 1.323.401, DJ 06.05.2016) que ganhou destaque na mídia recentemente (BARCELO, 2017).

Ainda que a importação paralela não seja um tema novo enfrentado no judiciário, é curioso notar que as decisões não costumam adentrar, em sua grande maioria, na possibilidade de descrença na qualidade do produto, que ingressa de modo paralelo, pelo consumidor hipossuficiente nesta relação.

De mesmo modo, pretende-se demostrar que a condução do tema pelo judiciário, de modo precário, ou incompleto, pode motivar a redução do investimento nas indústrias afetadas, assim como pode favorecer o comportamento parasitário que é nocivo para o ambiente comercial como um todo.

Portanto, diante de um cenário marcado por incertezas, ainda que não haja comprovação de contrafação ${ }^{1}$, o presente estudo pretende apontar para a necessidade de

\footnotetext{
${ }^{1}$ A contrafação pode ser conceituada como ato de falsificar, reproduzir ou imitar fraudulentamente um bem pertencente a outrem, comercializando-o sem autorização, em clara usurpação de direito alheio.
} 
parâmetros mais claros no bojo das decisões, explorando aspectos ainda silenciados, em busca de maior segurança jurídica sobre o tema cuja prática afeta diversos mercados.

\section{IMPORTAÇÃO PARALELA: CONCEITUTAÇÃO, VANTAGENS E DESVANTAGENS}

Para uma compreensão ampla sobre o tema é importante primeiro compreender o que é a importação paralela. Do ponto de vista conceitual, parte-se da ideia geral de que o comércio paralelo geralmente é uma ação de agentes econômicos independentes. Estes agentes econômicos, por meio de diversas formas, importam produtos que possuem a mesma marca de produtos já oferecidos no mercado doméstico.

A figura abaixo ilustra a situação que ocorre na importação paralela:

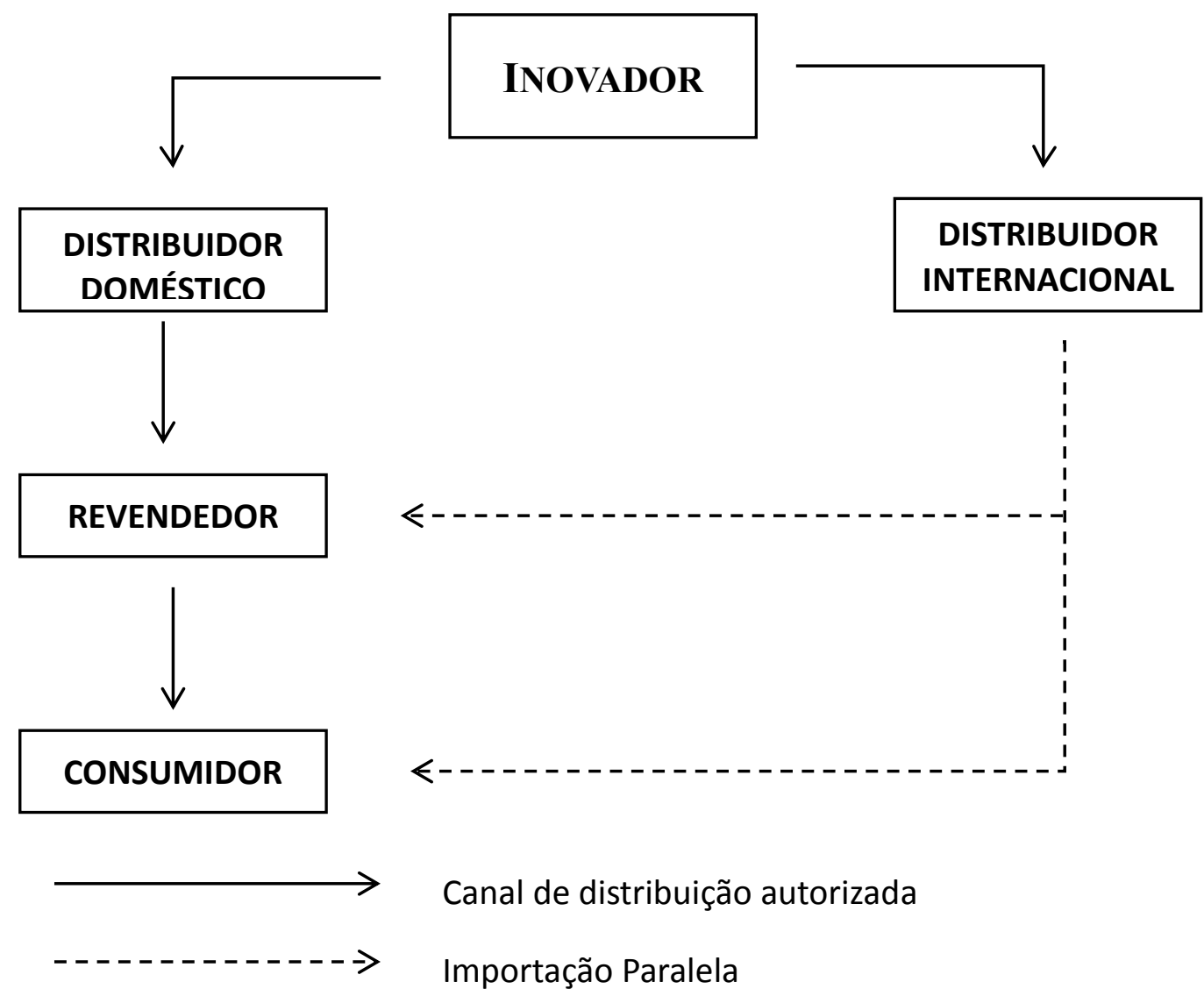


Entretanto, como vemos na ilustração acima, o problema inicia-se quando os produtos ofertados no mercado doméstico (via acordos de exclusividade, ou acordos de representação, por exemplo) são colocados pelos produtores nacionais ou pelos representantes da marca, sendo que estes se responsabilizam, também, pelas eventuais questões decorrentes do pós-venda de acordo com o Código de Defesa da Consumidor.

As importações paralelas ocorrem por uma outra via, já que os agentes são independentes, isto é, não tem ligação direta com os produtores ou representantes. Geralmente os importadores paralelos buscam colocar no mercado esses produtos com diferenças de preços.

O grande imbróglio que surge reside no fato de que a comercialização paralela é realizada, geralmente, sem violar as regras de comércio internacional. No entanto, as práticas de comércio paralelo também ocorrem sem a autorização direta do fabricante ou do representante da marca. Assim, surge o problema e a origem do termo "paralelo": muitas vezes passa a ocorrer uma concorrência intramarca que envolve bens que já dispõem de alguma distribuição oficial no país a que se destinam.

Ora, mas isto é legal ou ilegal? Em sendo uma conduta permitida, como os produtores podem se proteger se do ponto de vista do comércio ela não é vedada? E mais: no caso de necessidade de reparação, decorrente de defeito do produto $^{2}$, a quem é atribuída a responsabilidade do pós-venda?

Veja-se, então, que o problema não reside apenas nas diferenças de preços entre as mercadorias oficialmente distribuídas em um país e aquelas provenientes de importação paralela, muito menos da mera concorrência entre o produto paralelo e aquele comercializado por meio das representantes das marcas internacionais.

De fato, ao fazermos uma análise mais profunda das importações paralelas emergem outros aspectos sensíveis. Nesse sentido, não podemos nos esquecer dos custos com os representantes legalmente autorizados das marcas, tais como: i. divulgação comercial do produto, ii. os dispêndios relacionados à assistência técnica (desde um simples reparo até a troca do produto, sendo que muitos possuem garantia), iii. manutenção pós-venda, iv. treinamento de vendedores, v. pagamento de royalties, vi. investimentos em pesquisa e desenvolvimento (P\&D).

\footnotetext{
${ }^{2} \mathrm{O}$ termo defeito é adotado no presente artigo de forma a abranger tanto o próprio conceito de defeito $\left(\S 1^{\circ}\right.$ do artigo 12 do Código de Defesa do Consumidor - ausência de segurança) quanto o conceito de vício (artigo $18 \mathrm{cc}$ artigo 19 do Código de Defesa do Consumidor) que podem ser depreendidos do Código de Defesa do Consumidor.
} 
É exatamente da necessidade de garantia de parte ou até de outros aspectos mencionados, principalmente daqueles pautados na pesquisa e desenvolvimento, como também os custos de produção, que decorre a proteção conferida aos bens industriais. Assim, para o titular do produto emerge o direito de proteção do bem.

No contexto brasileiro, é a Lei de Propriedade Industrial (Lei 9.279/96) que busca trazer parâmetros em seu artigo 132, inciso III, ao estabelecer que o titular da marca não pode "impedir a livre circulação de produto colocado no mercado interno, por si ou por outrem com seu consentimento".

Segundo Basso (2009a, p. 177-178), este regramento introduziu no sistema brasileiro o conceito de exaustão dos direitos em nível nacional, em que após a primeira venda de determinado produto no mercado nacional o direito do titular sobre a marca se exaure, não podendo mais ser invocado o direito de exclusividade para, de alguma forma, impedir as vendas ulteriores.

Para a autora, as condições previstas no artigo 132, III, da LPI são objetivas: a) o mercado em questão é o nacional; b) o produto deve ser colocado no mercado nacional pelo titular da marca ou com o seu consentimento; c) o consentimento deve ser claro e inequívoco. Portanto, a ausência de um desses requisitos dá ao titular do bem o direito de buscar a defesa de seu produto, evidenciando-se evitar que "a venda ou importações paralelas atentem contra a unicidade, consistência e reputação de seu bem imaterial” (Id., Ibid).

Entretanto, há outra corrente, ao interpretar o mencionado dispositivo, que defende que a venda, no exterior, pelo titular da marca à terceira pessoa já exaure o seu direito de impedir que o comprador revenda o produto, direta ou indiretamente, para agente econômico situado no Brasil.

A interpretação neste caso seria a de Forgioni que defende que "o ato de alienação ocorrido no exterior é, incontestavelmente, a autorização a que se refere este o artigo 132, III, da Lei de Propriedade Industrial”. (2009, p. 218). De certo, aqueles que se filiam a esta compreensão evocam a "doutrina da primeira venda" (first sale) ao defender que o consentimento extrapola fronteiras e ocorre a partir do momento em que é realizada a primeira venda, não importando o país em que ocorreu a negociação (princípio da exaustão internacional).

Assim, para Forgioni, a autorização do detentor da marca é presumida a partir da realização da primeira venda no exterior, podendo o produto ser internalizado e vendido no 
Brasil. Em outras palavras, para esta corrente, o sistema jurídico opta pela admissão das importações paralelas.

A interpretação do dispositivo legal leva ao cenário internacional ilustrado abaixo (VOERMAN, 2014):

\section{Parallel Imports}

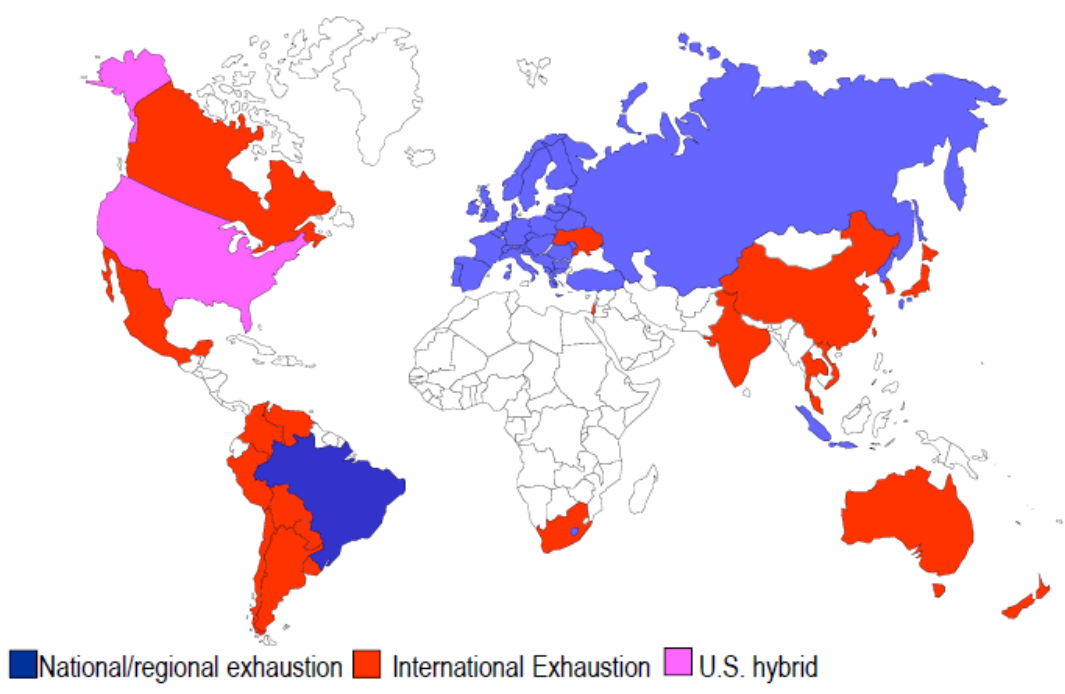

Nesse passo, a conceituação doutrinária da importação paralela pode ser compreendida juntamente com o tema da exaustão de direito que, para além da restrição dos direitos referentes à propriedade intelectual, traz consequências afetas ao direito concorrencial. Isto porque, o princípio da exaustão possui como finalidade o equilíbrio entre o direito do titular do bem e os interesses do mercado e dos consumidores.

Ora, pode ser verificado que a $\mathrm{LPI}^{3}$ não esclarece se o consentimento exigido deve ser expresso ou tácito, bem como não é clara quanto à extensão geográfica dos efeitos da exaustão, o que, sem dúvida, dá margem para interpretações divergentes, e que merecem um olhar crítico acurado.

Uma questão fortemente ligada a esta compreensão diz respeito à possibilidade de que os importadores paralelos invadam determinado mercado, impondo-se, de forma a dominá-lo. Assim, a participação de agentes econômicos que possuem autorização para importar e vender

\footnotetext{
${ }^{3}$ Art. 132. O titular da marca não poderá:

$[\ldots]$

III - impedir a livre circulação de produto colocado no mercado interno, por si ou por outrem com seu consentimento, ressalvado o disposto nos $\S \S 3^{\circ}$ e $4^{\circ}$ do art. 68 .
}

Rev. de Direito, Inovação, Propriedade Intelectual e Concorrência| e-ISSN: 2526-0014| Maranhão | v. 3 | n. 2 | p. 22 - 39 | Jul/Dez. 2017. 
determinado produto no Brasil passaria a ser reduzida. Destarte, abre-se uma senda onde os produtos importados pelos agentes autorizados competem internamente com os produtos oriundos da importação paralela.

Basso (2009b, p. 201-221), ao analisar os custos e benefícios da importação paralela para o comércio e desenvolvimento (dimensão econômica e social) apresenta os argumentos favoráveis e contrários à importação paralela.

Dentre os argumentos favoráveis destacam-se: criação de obstáculos à segmentação de mercados; produtos e serviços disponibilizados por preços mais baixos com benefícios para os consumidores; restrição à discriminação geográfica de preços (isto é, o mercado aberto à importação paralela tende a limitar a diferenciação do preço dos produtores em um determinado mercado); proteção do consumidor diante de eventuais abusos de preços; aumento da concorrência no mercado interno.

Já os argumentos contrários à importação paralela estão relacionados à manutenção da consistência e da qualidade do produto ou serviço (manutenção da qualidade do produto pelo detentor do bem, posto que produtos importados paralelamente podem não ter as mesmas especificações, podem ser modificados, podem não ser embalados de maneira adequada quando do transporte, bem como podem ser conservados em locais inapropriados e de forma inadequada); aos serviços de assistência e manutenção pós-venda (os produtores investem nestes serviços para garantir a qualidade dos produtos e serviços, garantindo também bom atendimento, troca e reparos de qualidade $)^{4}$; à descoberta de cópia ilícita; aos investimentos realizados pelo titular do bem ou serviços se torna seriamente ameaçado (investimento em pesquisa e desenvolvimento e na manutenção da qualidade) ${ }^{5}$. (Basso, 2009b, p. 201-221)

Com efeito, da análise dos dois posicionamentos apresentados e dos pontos favoráveis e contrários à importação paralela, verifica-se que de um lado se destaca o fundamento de incentivo à competição na medida em que a concorrência se torna salutar. De outro lado, há a identificação de instabilidade que determinado mercado pode vir a sofrer. As diferentes compreensões e interpretações apontadas trazem, em verdade, uma relação tênue entre a prática da concorrência desleal com o abuso de direito nas importações paralelas e o direito à livre concorrência.

\footnotetext{
${ }^{4}$ Os importadores paralelos, em sua grande parcela, podem não garantir esses benefícios ao consumidor.

${ }^{5} \mathrm{O}$ retorno do investimento pode ser reduzido pela prática da importação paralela, prejudicando os consumidores, posto que diminuem as escolhas e possibilidade e acarretam na redução dos investimentos em inovação. Este é o posicionamento dos autores deste artigo.
}

Rev. de Direito, Inovação, Propriedade Intelectual e Concorrência| e-ISSN: 2526-0014| Maranhão | v. 3 | n. 2 | p. 22 - 39 | Jul/Dez. 2017. 
Diante desse quadro de interpretações e fundamentações divergentes, compreendemos que necessariamente deve ocorrer uma análise sistemática, de forma a trazer concretude a uma análise da realidade da indústria e da necessidade de se assegurar os estímulos adequados à pesquisa e ao desenvolvimento.

\section{O PROBLEMA IDENTIFICADO À LUZ DA LPI E DA DEFESA DA CONCORRÊNCIA}

As importações paralelas, como visto acima, podem ser consideradas como uma via de mão dupla: ao mesmo tempo podem incentivar a competição, dentro do mercado de um país, também podem, por outro lado, promover a instabilidade no mercado. Os efeitos deletérios não são desprezíveis, já que se tratam de consequências que geram a redução do incentivo aos investimentos em inovação. Esse cenário, sem dúvida alguma, tem como efeito potencial a redução do desenvolvimento (Sen, 2010; Schumpeter, 1934).

A diferença de atuação daqueles que são os representantes das marcas e daqueles que são os importadores paralelos tem promovido várias discussões, no campo doutrinário e jurisprudencial, especialmente no que diz respeito aos efeitos líquidos sobre o bem-estar social ${ }^{6}$. Ou seja, há razoabilidade nessa conduta? Faz sentido a permissão indiscriminada desta prática no comércio internacional?

Existem na doutrina nacional alguns defensores da liberação das importações paralelas. Estes, de forma bastante discutível, entendem haver efeitos positivos sobre o ambiente concorrencial, o que traria benefícios aos consumidores, ao possibilitar preços de revenda mais baixos.

Contudo, entendemos que esse pensamento deixa de lado a importância em se proteger o produtor e os efeitos diretos em P\&D ao apenas entender que as importações paralelas

\footnotetext{
${ }^{6} \mathrm{O}$ conceito de bem-estar alude à ideia de qualidade de vida, e remete às condições sociais e econômicas necessárias para o desenvolvimento pleno do indivíduo no seio da sociedade. Do ponto de vista do Direito, relaciona-se com a provisão estatal dos direitos de segunda geração - direitos sociais, econômicos e culturais, que visam conferir uma igualdade material ao indivíduo (BULOS, 2012, p. 525), prestados por um setor típico do Estado moderno, conhecido como Estado de Bem-Estar Social (KAUFMANN, 2001, p. 21). No Brasil, o bemestar, junto com a justiça social, constitui objetivo da Ordem Social, conforme preconiza o Art. 193, da Carta Magna, penetrando as esferas relativas à educação, à cultura, à família, ao trabalho, à habitação, ao esporte, à seguridade social (saúde, previdência e assistência social), ao meio ambiente, à criança e ao adolescente, ao idoso, à ciência, aos índios e à comunicação social.
} 
restringiriam um suposto exercício de um potencial poder de mercado ${ }^{7}$ por parte dos representantes oficiais de marcas. Alinhada a essa vertente encontramos Forgioni que entende que as importações paralelas teriam papel "primordial para a preservação da concorrência e, consequentemente, para a coibição de abusos que poderiam ser perpetrados tanto pelos distribuidores quanto pelos fabricantes" (2007, p. 223).

Nesse sentido, não seria razoável avaliar os custos que os representantes de marcas incorrem e que não existem para os importadores paralelos? Ou, no mesmo contexto, seria adequado ignorar esses custos adicionais dos quais os importadores paralelos se isentam?

Ainda que possamos partir de um posicionamento liberal, a diferença de preços não parece ser motivo suficiente e adequado para a defesa deste posicionamento. ${ }^{8}$ Isto porque, ao se alegar que o comércio paralelo é bom, no sentido de se evitar um potencial abuso, olvida-se que os importadores paralelos passam a ter vantagens competitivas em relação aos representantes de marcas. Como bons exemplos podemos citar que os importadores paralelos não precisam anuir com a política empresarial da empresa, ou com os compromissos relacionados ao pós-venda de assistência ao consumidor.

Como natural consequência, os importadores passam a ter um lucro maior, ao menos potencialmente, devido à alternativa mais barata, que num contexto mais amplo, acaba por desestimular pesquisas em P\&D e o ambiente empresarial como um todo.

Trata-se, in casu, de um típico cenário conhecido como o "efeito carona" (freeriding $^{9}$ ): situação na qual um agente econômico "pega carona" em algum produto, serviço ou atividade decorrente do investimento de outro agente econômico, sem, contudo, pagar ou

\footnotetext{
${ }^{7}$ Poder de mercado é compreendido como um poder suficientemente grande de um agente econômico a ponto de conseguir agir de forma independente no mercado, de modo a não se preocupar com os comportamentos de outros agentes. (GABAN; DOMINGUES, 2016, p. 112).

${ }^{8}$ Ao analisar a abertura da importação paralela realizada pelos Estados Unidos após a criação da OMC, BASSO (2009a, p. 182 e ss) identifica que "a entrada de produtos iguais a preços reduzidos acaba desfavorecendo o produtor doméstico que arcou com investimentos para firmar seu mercado, registrar seus produtos, etc. O importador paralelo, ademais de gerar uma competição intramarcas, extremamente desfavorável, acaba corroendo e captando seu mercado sem arcar com os custos iniciais para a proteção dos direitos de propriedade intelectual, não se tratando, portanto, de concorrente considerado jurídica e economicamente caracterizado, pois não criou eficiência, tampouco investimentos hábeis para concorrer com um produto protegido no território americano".

${ }^{9}$ Segundo o Professor Calixto Salomão Filho, ao expor que a proteção à invenção industrial auxilia o estímulo criativo, conceitua o free-riding ou free-rider como "aproveitamento por parte daquele que não investiu na pesquisa dos resultados dela advindos" (2006, p. 14.). No mesmo sentido, FORGIONI $(2009$, p. 223) explica que o "fenômeno do free rider ocorre quando um adquirente recebe, sem qualquer custo, indicações ou serviços de um distribuidor [...], mas compra, por preço inferior, o bem desejado de outro que não the proporciona iguais facilidades", sendo este fato possível porque o segundo distribuidor não incorre nos mesmos custos do primeiro distribuidor. Segundo o Dicionário de Cambridge free ride é "an opportunity or advantage that someone gets without having done anything to deserve it" (Cambridge Dictionary. <http://dictionary.cambridge.org/pt/>. Acesso em 12 de agosto de 2017).
} 
investir qualquer valor. Essa ação gera a diminuição do incentivo para se manter alguns investimentos o que, em casos mais dramáticos, pode ter como resultado a saída do serviço ou do produto anteriormente oferecido no país.

Portanto, um dos elementos que provocou o presente estudo foi justamente a preocupação com a potencial redução de investimentos que, em uma reação em cadeia, impacta diretamente no desenvolvimento industrial de determinado setor, o que também traz externalidade negativas na qualidade dos produtos e serviços ofertados aos consumidores. Identifica-se, inevitavelmente, um risco ao bem-estar social.

Assim, parece ser equivocado o raciocínio de que, com base em preços possivelmente menores, as importações paralelas tendem a beneficiar os consumidores e, então, por isso devem ser permitidas. Do ponto de vista do direito econômico e propriamente do direito antitruste (também chamado de direito concorrencial) não merece prosperar essa compreensão até mesmo porque cada mercado possuiu características essenciais que diferem seus produtos e/ou serviços. Como exemplo temos o fato de que não são todos os tipos de mercado nos quais identificaremos a existência de posição dominante ${ }^{10}$, assim como não é possível verificar em todos os mercados os fatores de incentivo ao investimento em inovação.

Numa visão estrita, se as empresas de um determinado mercado são estimuladas a investir, em razão de uma suposta competição intramarca, isto é, numa situação decorrente de um cenário no qual o simples aumento do volume de negócios, envolvendo a mesma marca, representa ganhos ao fabricante, então as importações paralelas poderiam cumprir um papel importante na estrutura do setor. Ou seja, nessa situação hipotética, descrita aqui, as importações paralelas gerariam alguns ganhos ao bem-estar social.

\footnotetext{
${ }^{10}$ Posição dominante é "uma construção jurídica que vai indicar a linha tênue que separa um poder de mercado aceitável daquele que pode prejudicar a concorrência. [...] Em verdade, a existência de uma posição dominante é comprovada utilizando-se diversos fatores, dos quais nenhum é decisivo por si só, mas, sim, adquirem robustez quando combinados. O principal fator utilizado para estabelecer domínio é o market share da empresa em referência. Assim, diante de uma participação elevada no mercado relevante analisado, a crença na possibilidade de existência de poder de mercado é mais consistente, o que permite o avanço na análise para se verificar se é dado ao agente, detentor de elevada participação de mercado, atuar de forma independente e indiferente no mercado em análise". (GABAN; DOMINGUES, 2016. p. 112-115.). Salomão Filho (2003. p. 121-122.) compreende que haverá dominação de mercado todas as vezes que o consumidor tiver seu direito de escolha reduzido (limitação da concorrência em seu sentido institucional). Defende o autor que esta limitação ocorrerá quando "houver risco de exclusão de concorrente ou de colusão [acordos entre concorrentes, joint ventures, associação entre empresas] ente concorrentes que possa ter impacto sobre o mercado, limitando a escolha do consumidor". HAWK (1990, p. 788-789) traz a diferença entre posição dominante e poder de mercado e afirma que ambas são "legal constructs based on policy considerations which suggest where the line should be drawn between acceptable market power and suspect monopoly power".
} 
Entretanto, em um cenário no qual empresas de um determinado mercado apenas são motivadas a investir em inovação devido à competição intermarcas, parece ser evidente que as importações paralelas não deveriam prosperar pelo efeito carona, considerando que não há compartilhamento de benefícios com os consumidores.

Nesse sentido, os estudos de Valletti e Szymanski (2006) e de Malueg e Schwartz (1994) abordam bem o tema, uma vez que defendem que as importações paralelas devem ser proibidas considerando os seus efeitos sobre o bem-estar. Valletti e Szymanski (2006) não apenas analisam os efeitos da importação paralela sobre os preços, mas também os efeitos da qualidade dos produtos ofertados, considerando, em suma, que o mercado observará redução de preços apenas na hipótese de os representantes terem poder de mercado.

Os estudos mencionados acima parecem estar seguros de que é falacioso o argumento que indica que as importações paralelas elevam o bem-estar dos consumidores. A qualidade dos produtos e a dinâmica concorrencial são elementos que não podem ser deixados de lado (Valletti e Szymanski, 2006, p. 4), mas é um fato que esses elementos têm sido marginalizados em estudos sobre o tema.

O efeito não esperado seria justamente o de afastar esses agentes econômicos do mercado, que custeiam a marca e responsabilizam-se pelo pós-venda, já que estes estariam expostos aos produtos dos concorrentes (produtos importados). O efeito natural seria o movimento desses produtores, ou dos representantes das marcas no Brasil, no sentido de reduzir os gastos direcionado ao desenvolvimento do produto, já que os resultados positivos desses investimentos passam a ser compartilhados com aqueles que não tiveram nenhum esforço: os "caronas".

Nesse sentido, é importante observar algumas decisões judiciais do Tribunal de Justiça do Estado de São Paulo, favoráveis às importações paralelas ${ }^{11}$, ilustrando casos nos quais os distribuidores brasileiros autorizados não precisavam de investimentos para o incremento da qualidade do produto ou do serviços pós-venda.

Sendo assim, ao compreender que o universo de atividades e de mercados que sofrem com importações paralelas deve ser analisado de forma casuística (case by case), passa a ser salutar a comparação dos aspectos positivos, que estariam ligados à uma suposta mitigação do

\footnotetext{
11 TJSP, Apelação 75.002-1, RJTJSP 106/135, Desembargador: Juiz Luis de Macedo, 1986 (Caso Bolla); TJSP, $3^{\text {a }}$ Câmara de Direito Privado de Férias, Apelação 9074130-76.1998.8.26.0000, Relator: Desembargador Carlos Roberto Gonçalves, j. 28.01.2000 (Caso Vodka Wyborowa); TJSP, $4^{\text {a }}$ Câmara de Direito Privado, Apelação n. ${ }^{\circ}$ 0082979-49.2005.8.26.0000, Relator: Desembargador Enio Zuliani, j. 27.04.2006 (Caso Charutos Havana).
} 
poder de mercado dos representantes de uma marca, com os aspectos negativos, que estariam ligados ao suposto desestímulo à pesquisa e ao investimentos decorrente da atuação dos free riders, o que inegavelmente traduz fatores que podem afetar a reputação da marca.

\section{ANÁLISE DA JURISPRUDÊNCIA RECENTE}

Como forma de contribuir com o tema, a análise jurisprudencial realizada teve como enfoque os votos dos Ministros do Superior Tribunal de Justiça (STJ), especialmente no que concerne aos casos recentes sobre o tema.

Nesse sentido, o termo chave utilizado na busca foi "importação paralela". A partir da análise realizada, a parte final deste estudo apresentará um breve panorama do entendimento do STJ sobre a importação paralela nos últimos anos.

Nesse contexto, destacaremos a primeira decisão do STJ que diz respeito à importação paralela no setor da moda, que é uma das industrias mais preocupadas com a pesquisa e a inovação, sendo esta também uma das decisões mais recentes sobre a temática da importação paralela (STJ, REsp n. ${ }^{\circ}$ 1.323.401, DJ 06.05.2016).

\subsection{Posicionamentos do STJ sobre a importação paralela}

Na pesquisa realizada foi possível observar que o Superior Tribunal de Justiça compreende que a importação paralela de produtos é, em regra, vedada pelo ordenamento jurídico (art. 132, II, da Lei n ${ }^{\circ}$ 9.279/96), reconhecendo nos casos de ausência de consentimento expresso a concorrência desleal.

O conceito de importação paralela é analisado também a partir das reivindicações dos titulares dos bens em relação aos custos, bem como sob o aspecto do consumidor, que possui o direito de ter um produto de qualidade, acesso à assistência técnica e, a depender do caso, reposição do produto. ${ }^{12}$

Entretanto, o STJ reconhece a licitude da importação paralela quando a importação é realizada por um determinado tempo e sem qualquer oposição do titular da marca ou do agente autorizado $^{13}$, sob o fundamento de que "a interpretação que exige menor rigor formal no

\footnotetext{
${ }^{12}$ STJ, REsp n. ${ }^{\circ} 1.207 .952$.

${ }^{13}$ STJ, REsp n. ${ }^{\circ} 1.249 .718$ (Caso Johnie Walker) (“Tendo em vista o longo período de realização de importações paralelas, mediante contratos firmados no exterior com o produtor titular do direito da marca ou com quem tinha
} 
consentimento é mais ajustada ao princípio constitucional da liberdade da atividade econômica"

(STJ, REsp n. $\left.{ }^{\circ} 1.200 .677\right)$.

O Voto-Vista assinalou admitir ser ilegal a importação paralela não autorizada, e nesse ponto não há a contradição com o Voto Relator, que também admitiu a ilegalidade desse tipo de importação, mas, no caso, admitiu a validade da importação paralela realizada, visto que, afinal de contas, durou ela continuamente por cerca de quinze anos, com conhecimento e tolerância da Ré, quer dizer, por esta autorizada. [...]

Em suma, embora no sistema marcário sejam em regra ilegais as importações paralelas sem autorização do titular da marca, no caso entendeu-se por havida essa autorização ante o conhecimento e tolerância por numerosos anos, fixando-se o dever de indenizar pela cessação sem fixação de prazo na notificação, que se assemelharia ao de seis meses típico do contrato de revenda, contando-se esse prazo a partir da data em que tornada inequívoca a oposição (que poderá ser a da notificação ou a da citação, ou outra, segundo, como ressaltado no Acórdão, "de acordo com os costumes do mercado"). (STJ, EDcl nos EDcl no Recurso Especial N 1.200.677)

Portanto, verifica-se uma tendência do STJ em seguir analisando os casos de importação paralela caso a caso, tendo em vista a admissão da prática quando a sua realização ocorre(u) por um longo período e com tolerância do titular, questão que voltaremos adiante.

\subsection{O "Caso Diesel" - um exemplo do posicionamento do STJ em casos que envolvem a indústria da moda}

O “Caso Diesel” (STJ, REsp n. ${ }^{\circ}$ 1.323.401, DJ 06.05.2016) é um caso relativamente recente, paradigmático, que foi analisado pelo STJ. Em referido caso o mercado analisado refere-se às roupas e peças de vestuários da marca Diesel S.p.A ("Diesel").

A empresa Vintage Denin Assessoria Empresarial Ltda., distribuidora exclusiva da referida marca no Brasil, ingressou com ação contra Eliana Toledo Gomes de Mattos Bolsas e Artigos de Vestuário - Microempresa alegando que esta estaria importando e comercializando produtos da marca Diesel sem qualquer autorização, caracterizando importação paralela vedada pelo ordenamento jurídico pátrio.

o consentimento deste para comercializar o produto, e, ainda, a ausência de oposição por aludido titular ou do representante legal no Brasil, não é possível recusar abruptamente a venda do produto ao adquirente, dada a proibição de recusa de vender, constante dos artigos 20, da Lei 8.884/94 e 170, IV, da Constituição Federal"). Neste julgado, o STJ reconheceu a legalidade da importação paralela pela ausência de oposição formal, mas reconheceu o direito das titulares da marca de colocarem fim à importação paralela praticada pelo agente importador paralelo.

Rev. de Direito, Inovação, Propriedade Intelectual e Concorrência| e-ISSN: 2526-0014| Maranhão | v. 3 | n. 2 | p. 22 - 39 | Jul/Dez. 2017. 
Assim, considerando que a comercialização não era autorizada, a Autora requereu a abstenção por parte da Ré do comércio e importação de toda e qualquer mercadoria referente à marca e também a condenação de indenização por danos morais e materiais.

Em primeira e segunda instância identificamos decisões desfavoráveis sob os seguintes argumentos: i. o contrato de exclusividade assinado com a detentora da marca não gera nenhum efeito perante terceiros; ii. a aquisição dos produtos pela Ré diretamente em lojas no exterior traz consigo o consentimento tácito e não houve nos autos a comprovação de contrafação.

O Ministro Marco Aurélio Belizze, relator do acórdão, entretanto, em sede de Recurso Especial, decidiu pelo parcial provimento ao recurso interposto pela empresa Vintage Denin Assessoria Empresarial Ltda., condenando a empresa Eliana Toledo Gomes de Mattos Bolsas e Artigos de Vestuário - Microempresa à indenização por danos patrimoniais em virtude da ilicitude da importação paralela.

Para o Ministro, a empresa Eliana Toledo, por meio de sua sócia, adquiriu produtos da marca Diesel no exterior a preços mais atrativos para, assim, revendê-los no mercado brasileiro. O Ministro anotou que a prática se caracterizava como importação paralela explicando que "as instâncias ordinárias a consideraram lícita por haver consentimento, ainda que tácito, da marca para que a recorrida revendesse suas mercadorias no território brasileiro" (STJ, REsp n. ${ }^{\circ}$ 1.323.401, DJ 06.05.2016, p. 3). Ressaltou que, apesar do entendimento do STJ no sentido de que deve ser afastada a ilicitude da importação paralela quando esta prática é realizada por espaço de tempo e sem oposição do titular da marca ou de terceiro autorizado, na hipótese dos autos "não houve tolerância por parte do titular da marca ou de seu representante quanto à importação paralela, e sequer houve autorização expressa, de quem poderia concedê-la, para a importação e comercialização dos produtos da marca Diesel S.p.A” (STJ, REsp n. ${ }^{\circ}$ 1.323.401, DJ 06.05.2016, p. 4), afastando, portanto, aplicação do entendimento mencionado.

Logo, a decisão deixou claro que:

[...] as importações paralelas só poderão ser consideradas lícitas quando houver contrato firmado com o titular da marca no exterior, ou com quem tem o consentimento deste para comercializar o produto em território nacional, o que não ocorreu in casu, devendo ser afastada aplicação do artigo 132, inciso III, da Lei 9.279/96.

Conforme noticiado, a decisão foi comemorada (BACELO, 2017), pois trata-se de precedente de suma importância: a primeira decisão sobre importação paralela no setor da moda, altamente preocupada com pesquisa e inovação. 
A decisão do STJ também trouxe uma compressão mais evidente que se filia ao posicionamento de que a revenda no mercado nacional brasileiro, de produtos adquiridos no exterior, depende do consentimento do agente proprietário da marca ou de agente por ela autorizado. Sendo assim, a decisão indicou a importância em se preservar os efeitos do contrato de exclusividade entabulado entre as empresas estrangeira e brasileira.

\section{CONSIDERAÇÕES FINAIS}

Como pode ser observado, o tema da importação paralela ganhou novos contornos com a decisão do STJ no caso Diesel. Entretanto, o STJ ainda não adentrou em questões que deveriam ser discutidas e que são sensíveis ao tema, tais como: i. responsabilização do titular da marca, ii. possibilidade de descrença na qualidade do produto pelo consumidor, iii. desestímulo ao investimento e espaço para atuação de free-riders, iv. análise de mercado para verificar se há poder de mercado. Estes temas também não foram enfrentados no acórdão analisado, indicando que ainda encontramos lacunas não preenchidas para uma compreensão completa sobre o tema.

Outra questão que chama atenção, e que está explicitamente citada no caso paradigmático analisado, é que a necessidade da autorização do titular da marca para que terceiro possa importar, no entendimento do STJ, possui a seguinte exceção: licitude da importação paralela quando esta prática é realizada por espaço de tempo e sem oposição do titular da marca ou de terceiro autorizado. Em outras palavras, a ausência de oposição do titular da marca, ou de seu representante autorizado, por longo período, pode caracterizar consentimento tácito e legitimar as importações realizadas.

No entanto, tal como se extraiu da análise do caso Diesel, o STJ não delimita qual seria esse período. Então, podemos presumir que essa questão também será discutida e analisada caso a caso? Diante da compreensão da ilicitude talvez seja o momento do STJ se posicionar especificamente sobre o tema, trazendo critérios para essa delimitação temporal, ou pelo menos elementos mais concretos para os produtores e representantes autorizados que operam no Brasil, sob pena de prevalecer a insegurança jurídica.

O posicionamento do STJ sobre a oposição do titular da marca ou de seu representante autorizado é outro assunto bastante intricado no que diz respeito às importações paralelas. Há uma grande dificuldade do titular do bem e do agente econômico autorizado na sua fiscalização, mormente quando envolve pequenas empresas, vendedores autônomos ou microempresários, 
casos em que o conhecimento da conduta que se subsume ao caso de importação paralela pode chegar ao conhecimento tardiamente.

Assim, verifica-se que ainda não há uma jurisprudência que se possa considerar consolidada, bem como há questões que devem ser enfrentadas para o bem da pesquisa e desenvolvimento. Nesse sentido, seria ideal a definição de critérios mais objetivos, ainda que permaneça à analise caso a caso, aproximando-se (o que não corre, de fato) do enfrentamento da questão sob a ótica da eliminação de eventual poder de mercado dos representantes de marca (i.e. casos em que a importação paralela pode incrementar a concorrência e proporcionar o bemestar dos consumidores e - por que não? - propriamente do mercado) e sob a ótica da manutenção do estímulo ao investimento, seja por parte do detentor da marca ou de seu representante autorizado.

\section{REFERÊNCIAS}

BACELO, Joice. Revenda de importado depende de aval da marca. Valor Econômico, São Paulo, 07 ago. 2017. Legislação e Tributos. Disponível em: $<$ http://www.valor.com.br/legislacao/5069718/revenda-de-importado-depende-de-aval-damarca>. Acesso em: 13 ago. 2017.

BASSO, Maristela. A importação paralela e o princípio da exaustão - especial referência às marcas. In: GRAU-KUNTZ, Karin; BARBOSA, Denis Borges (organizadores). Ensaios sobre o Direito Material: estudos dedicados a Newton Silveira. 169-208. Rio de Janeiro: Editora Lumen Juris, 2009a.

Importação paralela: efeitos no comércio internacional e nos direitos de propriedade intelectual. São Paulo, [s.n.], 2009b.

BRASIL. Lei n ${ }^{\circ}$. 9.279, de 14 de maio de 1996. Lei de Propriedade Industrial. Disponível em: <http://www.planalto.gov.br/ccivil_03/leis/19279.htm>. Acesso em: 07 out. 2016.

, Superior Tribunal de Justiça. Recurso Especial n. ${ }^{\circ}$ 1.323.401, Relator: Min. Marco Aurélio Bellizze, Recorrente: Vintage Denim Assessoria Empresarial Ltda. - Microempresa, Recorrido: Eliana Toledo Gomes de Mattos Bolsas e Artigos de Vestuario, Brasília, 12.04.2016, publicado no DJe 06.05.2016. Disponível em: <https://ww2.stj.jus.br/processo/revista/documento/mediado/?componente=MON\&sequencial $=60083178 \&$ num_registro=201200993060\&data=20160506 $>$. Acesso em: 13 ago. 2017.

Superior Tribunal de Justiça. Recurso Especial n. ${ }^{\circ}$ 1.207.952, Relator: Min. Luiz Felipe Salomão, Recorrente: Ativa Indústria Comércio e Importação Ltda., Recorrido: Konica Minolta Business Solutions do Brasil Ltda., Brasília, 23.08.2011, publicado no DJe 01/02/2012. 

$<$ https://ww2.stj.jus.br/processo/revista/documento/mediado/?componente=ATC\&sequencial $=17120953 \&$ num_registro=201001446898\&data=20120201\&tipo=91\&formato $=P D F>$. Acesso em: 14 ago. 2017.

Superior Tribunal de Justiça. Recurso Especial n. ${ }^{\circ}$ 1.249.718, Relator: Min Sidnei Beneti, Recorrente: Diageo Brands BV e Outro, Recorrido: GAC Importação e Exportação Ltda., Brasília, 18.12.2012, publicado no DJe 12.03.2013. Disponível em: $<$ https://ww2.stj.jus.br/processo/revista/documento/mediado/?componente=ATC\&sequencial $=20934370 \&$ num_registro $=201100484345 \&$ data $=20130312 \&$ tipo $=51 \&$ formato $=P D F>$.

Acesso em: 14 ago. 2017.

Superior Tribunal de Justiça. Recurso Especial n. ${ }^{\circ}$ 1.200.677, Relator: Min Sidnei Beneti, Recorrente: Diageo Brands BV e Outro, Recorrido: GAC Importação e Exportação Ltda., Brasília, 18.12.2012, publicado no DJe 12.03.2013. Disponível em: <https://ww2.stj.jus.br/processo/revista/documento/mediado/?componente=ATC\&sequencial $=20922517 \&$ num_registro $=201001235334 \&$ data $=20130312 \&$ tipo $=51 \&$ formato $=P D F>$.

Acesso em: 14 ago. 2017.

, Superior Tribunal de Justiça. Recurso Especial n. ${ }^{\circ}$ 1.200.677, Relator: Min Sidnei Beneti, Recorrente: Diageo Brands BV e Outro, Recorrido: GAC Importação e Exportação Ltda., Brasília, 05.12.2013, publicado no DJe 25.02.2014. Disponível em: < https://ww2.stj.jus.br/processo/revista/inteiroteor/?num_registro=201001235334\&dt_publicac ao=25/02/2014>. Acesso em: 14 ago. 2017.

BULOS, Uadi Lammêgo. Curso de Direito Constitucional. 7. ed. Rev. e Atual. São Paulo: Saraiva, 2012.

CAMBRIDGE DICTIONARY. Disponível em: <http://dictionary.cambridge.org/pt/>. Acesso em: 12 ago. 2017.

CAVAlIERI FILHO, Sergio. Programa de Responsabilidade Civil. 7. ed. São Paulo: Atlas, 2007.

FORGIONI, Paula A. Direto concorrencial e restrições verticais. São Paulo: Revista dos Tribunais, 2007.

Importações paralelas no Brasil: a propriedade industrial nos quadrantes dos princípios constitucionais. In: GRAU-KUNTZ, Karin; BARBOSA, Denis Borges (Org.). Ensaios sobre o Direito Material: estudos dedicados a Newton Silveira. Rio de Janeiro: Editora Lumen Juris, 2009. p. 209-229.

GABAN, Eduardo Molan; DOMINGUES, Juliana Oliveira. Direito antitruste. 4. ed. São Paulo: Saraiva, 2016.

GAEDE, Helena Candida Lisboa. Importação paralela e concorrência desleal. Revista da Associação Brasileira de Propriedade Intelectual. n. 83, jul./ago., 2006. 
GANSLANDT, Mattias and MASKUS, Keith E. Intellectual Property Rights, Parallel Imports and Strategic Behavior. 2007. Disponível em: <SSRN: http://dx.doi.org/10.2139/ssrn.982241>. Acesso em: 14 ago. 2017.

HAWK, Barry E. United States, common market and international antitrust: a comparative guide. $2^{\text {nd }}$ edition, Aspen Law \& Business, 1990.

KAUFMANN, Franz-Xaver. Towards a theory of the welfare state. In: LEIBFRIED, Stephan. (Ed.). Welfare State Futures. Cambrigde: Cambridge University Press, 2001.

MALUEG, D; SCHWARTZ, M. Parallel Imports, Demand Dispersion and International Price Discrimination. Journal of International Economics, 37, pp. 167-195, 1994.

SALOMÃO FILHO, Calixto. Direito concorrencial - as condutas. 1.ed. São Paulo: Malheiros Editora, 2003.

. Direito industrial, Direito Concorrencial e Interesse Público. Revista CEJ, Brasília, n. 35, p. 12-19, out./dez. 2006.

SCHMIDT-PFITZNER, Jan Hendrik. Trade-Related Aspects of Intellectual Property Rights. In: STOLL, Peter-Tobias; BUSCHE, Jan; AREND, Katrin (Ed.). WTO - Trade-Related Aspects of Intellectual Property Rights Edited by Peter-Tobias Stoll Jan Busche and Katrin Arend. Boston: Martinus Nijhoff Publishers Leiden, 2009. p. 316-330.

SEN, Amartya. Desenvolvimento como liberdade. (trad. Laura Teixeira Motta). São Paulo: Companhia das Letras. 2010.

VALLETTI, Tommaso, M.; SZYMANSKI, Stefan. Parallel trade, international exhaustion and intellectual property rights: a welfare analysis. 2006. Disponível em: <http://citeseerx.ist.psu.edu/viewdoc/download?doi=10.1.1.605.5807\&rep=rep1\&type=pdf.> Acesso em: 11 ago. 2017.

VOERMAN, Anne. Stand up against illicit parallel trade - part I. Outubro de 2014. Disponível em: <http://blogs.dlapiper.com/legalblognl/2014/10/07/stand-up-against-parallel-import-parti/> Acesso em: 20 ago. 2017.

SCHUMPETER, J. A. The Theory of Economic Development: an inquiry into profits, capital, credit, interest and the business cycle. 2. ed. Cambridge: Harvard University Press, 1934. 